\title{
Dealing with Cultural Identities: A Study of Nepalese Families in Tokyo ${ }^{1}$
}

\section{Mehta Kalu Singh}

\begin{abstract}
In recent years, the Nepalese migrant population in Japan has increased exponentially. The number reached 88,951 in 2018, becoming the largest south Asian population in Japan. This number includes people in various visa categories: skilled labor, engineer, business, dependent, student and so on. The number of school children lies somewhere around 10,000. A child born and raised in a culture different to their parents' culture goes through a complex cultural identity formation process. In this context, this paper explores children's cultural identity development and promotion by migrant Nepalese families in Tokyo. In particular, it examines which cultural identities they are prioritizing and how they are developing host cultural identities while maintaining their native culture. The experiences of these migrant Nepalese parents were collected through indepth interviews with 45 parents. The responses suggest that these parents are prioritizing the promotion of a Nepalese cultural identity for their child(ren). Parents focus on promoting and participating in Nepalese festivals, cooking Nepalese food at home, and meeting other Nepalese families in Japan. However, almost every parent expressed their desire for the development of a multicultural sense in their child(ren).
\end{abstract}

Keywords: Cultural identities, migrants, Nepalese families, children

\section{Introduction}

Both Nepal and Japan are Asian countries with strong cultural and spiritual bonds, signified by the introduction of Buddhism in Japan around the $6^{\text {th }}$ century. The first Nepalese officially came to Japan in 1902 (Meiji 35 Era), when the government of

\footnotetext{
${ }^{1}$ Cite this article as: Mehta, K. S. (2021). Contemporary Research: An Interdisciplinary Academic Journal, vol. 5 (1); DOI: https://doi.org/10.3126/craiaj.v5i1.40482

Mehta Kalu Singh, Daito Bunka University, Japan; Email: winnersaru@ gmail.com

Article history: Received on May 4; Accepted on September 16; Published on October 21

Peer reviewed under the authority of CRAIAJ, academic journal of Ghodaghodi Multiple Campus, Kailali, Nepal, with ISSN 2717-4611 (Print) and ISSN 2717-462X (Online).

(C) 2021 CRAIAJ
}

Full text of this article can be downloaded from www.craiaj.com and www.nepjol.info 
Nepal decided to send 8 Nepalese students to Japan to study various technical subjects. The number of students increased in 1956 after the Monbukagakusho (MEXT) scholarship was made available to Nepalese students by the Japanese government. NepalJapan diplomatic relations were established in September 1956 through opening their embassies in both countries.

The Nepalese population in Japan has been increasing exponentially since 2000, reaching 6,953 in $2005 ; 17,525$ by $2010 ; 31,537$ in 2013 ; and 88,951 by 2018 (Immigration bureau of Japan, 2018), of whom 28,987 are on student visas and 26,017 are on dependent visas. A significant number are school-age children.

The number of Nepalese in Japan

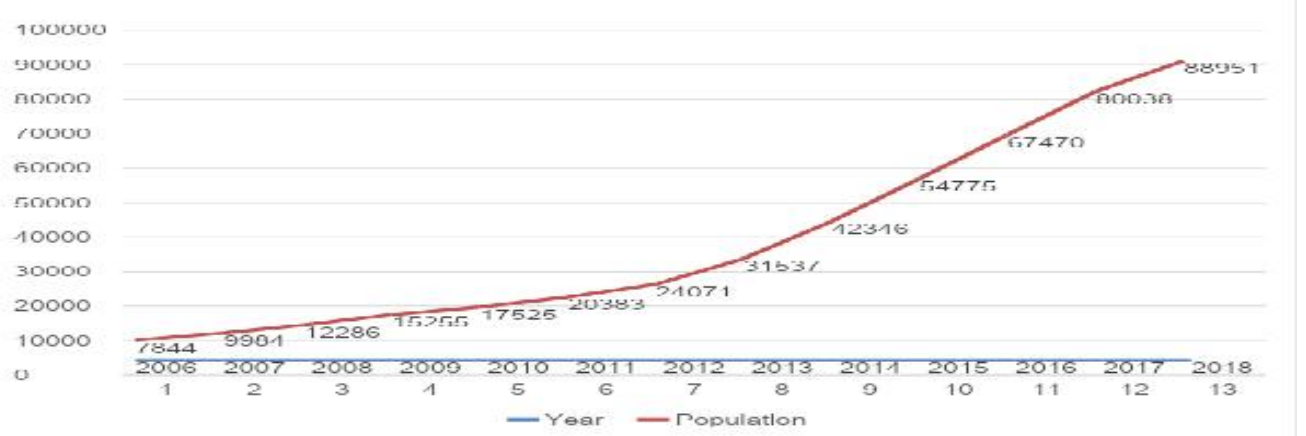

Bureau of Statistics of Japan (2018)

People who migrate to a new country usually have to negotiate customs and practices of the host/local culture as well as the national/ethnic cultural identity. Among these customs and practices are language and cultural norms, such as food, festivals, clothing, and written documents, etc. In past decades, it was somewhat difficult to find the original things from their culture in their new country, but the development of highspeed technology and globalization has worked positively in transforming access to ethnic culture. Culture created in the globalized context has been defined as globalized culture through which children are able to eat similar foods, read similar books, listen to the same music and watch the same television shows (Hall, 1993). On the other hand, MacDougal (2003) said that cultural traditions, customs and practices are integrated into the local customs and practices. For example, tea and coffee are globally available drinks 
but they differ in taste or variety depending upon the place or country. The coffee in Japan is more integrated towards the Japanese society or sometimes productions are glocalized according to the preferences of the customers, which may be different than in other countries. It is common to drink tea in Nepal (sometimes with sugar and milk), but coffee is more common in Japanese society. These small things play a significant role to migrant families, who have to deal with customs from both cultures at the same time, in some contexts to maintain their home culture due to the influence of the host culture where their children are raised.

Emerging immigration and globalization have much influence on cultural identity formation. It is a particularly complex issue for migrant children and adolescents. Media such as television, movies, music and internet are the major factors to the contribution of the rapid and extensive spread of ideas across cultures (Dasen, 2000). The age of adolescent and emerging adulthood is a major time to move towards the diverse culture because they have not yet settled on particular beliefs (Arnett, 2000). Some research with immigrants in United States has shown that adolescents are more cohesive towards acculturation than other immigrants or other adolescents if they are exposed to globalization (Nguyen \& Williams, 1989).

Cultural identity is a part of social identity that distinguishes one as a member of a cultural group or a group of individuals defined by sharing a cultural heritage (Schwartz, Montgomery \& Briones, 2006). Cultural identity can be defined as one's affiliation with a particular ethnic group and with a nation (Phinney, 1990). But in the case of ethically mixed people or those who have moved to another country, cultural identities mean affiliating to different ethnic groups and with more than one nation (Phinney, Horenczyk, Liebkind, \&Vedder, 2001). There are various aspects related to the cultural identity of immigrants: a sense of belonging to any shared value and belief, attitude towards the ethnic group and nation, and one's involvement and commitment to the group (Phinney \& Ong, 2007; Schwartz et al., 2006). This includes sharing a language, religion, participating certain traditions and rituals, knowledge of gathering and communications, and one's ethnic and national history (Lal, 1995; Schwartz et al., 2006).

Migrant cultural identity was defined theoretically as a bipolar model (Eisenstadt, 1995), which assumes that the immigrant comes to the host country with a single identity

Full text of this article can be downloaded from www.craiaj.com and www.nepjol.info 
or their origin country's identity but in the process of settlement their country's identity becomes weaker due to the influence of the host country's identity. This model argues that the process of identity formation becomes more contradictory, where one increases at the expense of the other. The bipolar model is also related to two psychological theories: Erikson's (1968) personal identity theory, and Tajfel and Turner's (1986) social identity theory. Personal identity theory assumes identity development to be a main part of the individual. Erikson assumes that a healthy identity should be strengthened and stable and should remain stable across life. Erikson identifies a danger of immigration; the process of constructing a new identity can lead to an unstable sense of self before leading to an optimal sense of psychological functioning (Akhtar, 1994). Therefore, a solution for immigrants is to renounce their old identity through a mourning process and develop a new cultural identity of the host country. Sociological theory on the resocialization-of immigrants also suggests that maintaining two different cultures is impossible, because of the differences in culture (Eisenstadt, 1995; Bar-Yosef, 1968). Adoption of the host country's cultural identity and cultural practices will help to adjust to the host society. Alba \& Nee (1997) consider that discrimination against immigrants and policies of segregation are the major factor that are preventing immigrants to assimilate in the host culture. Arnett (2002) states that most people in the world now develop a bicultural identity; where part of their identity is rooted in their local culture and another part is based on the awareness of multiculturalism.

\section{Methods}

This study was a part of master's thesis which was submitted to Daito Bunka University, graduate school of foreign language, titled "Language Practice and Cultural Identity: A study of Nepalese families in Japan". This research study takes the form of an exploratory study where a qualitative approach was followed to gather and analyze the participants' experiences and practices (Creswell, 2012) regarding the cultural identity of their child(ren). The method of data collection was qualitative in-depth interviews with migrant Nepalese parents' who are raising their child(ren) in Tokyo. One of the parents (either the mother or the father) was interviewed for this study. A total of 45 parents were interviewed for this study among them 16 were the mothers and 29 were the fathers. The larger number of fathers was largely due to the fact that the researcher is a male and in a better position to access more fathers than mothers. The age group also varied; 12 were in their 40s, 32 in their 30s and 1 parent was in their late 20s.

Full text of this article can be downloaded from www.craiaj.com and www.nepjol.info 
The purpose of the interviews was to explore parental ideologies and practices regarding the cultural identity development of their child(ren). All respondents were informed about the purpose of the study and consent for interview was received from them. The interviews were conducted by the researcher and most of the interviews were taken in the Nepali language (the official language of Nepal) due to the ease for the interviewees. Later those interviews were translated into English by the researcher. Interviews were semi-structured and had both open-ended and closed-ended questions. The questions focused on which cultural identity they were focusing on for their child(ren), why they chose that identity, and what sort of plans or strategies they were implementing to accomplish this identity development. Some questions asked which food they cooked and ate, what TV they watch at home, what festivals they celebrated, and whether they encouraged their child(ren) to participate in Japanese or Nepalese social events.

Generally, interviews lasted anywhere from forty minutes to an hour. All interviews were conducted on a one-to-one basis. The interviews started with a brief summary of the interview's purpose, the interviewer's credentials, and the nature of the information needed. Interviewees were also told about the data usage and confederal of the data taken from them. Throughout each interview, a cordial, non-threatening and trusting environment was maintained to allow participants to express their opinions freely. Interviews were taken having coffee or food and amongst conversation about their daily life or life experiences in Japan and how they are dealing with their child(ren)'s overall development. In other words, data was gained more through indirect conversation rather than asking directly this or that. The interviews were followed by a phone call thanking each interviewee again and sometimes clarifying any questions that remained. The first few respondents were selected through the researchers' personal network as the researcher belongs to this Nepalese migrant group. At the conclusion of each interview, interviewees were requested to introduce other Nepalese families who are living in Tokyo. In this way, snowball sampling was used to expand the number of respondents. The researcher also visited some cultural events organized by Nepalese organizations to better understand the practical issues for migrant Nepalese in raising their child(ren) in Japan. 
This study mainly focuses on the responses of the interviewed parents. Each of the interviews was transcribed and coded. First, the raw data were organized according to each area of inquiry. A spreadsheet was used to organize data for this study. For closedended questions, charts and table were created to demonstrate parents' views on certain areas, such as which language they use at home. Parents' answers were managed by chart for this category and then parents were asked why they are focusing on that cultural identity using as an open-ended question. Those open-ended responses were analyzed and compared to the respondents' demographic and ideological contexts. Then, all data were read through to gain an overall sense of the information. After that, data were managed according to the contexts, process and their relationship within family as well as societal contexts. Once the data were managed, description of themes were generated based on the nature and frequency of collected data, such as the mother tongue of family and parents' current attitudes and practices towards their mother tongue and other social languages.

\section{Results and Discussion}

The data collected through interviews with these migrant Nepalese parents point to some of the general themes in developing their children's cultural identities. Almost all parents are promoting Nepalese cultural identity among their children no matter what the individual family situation. When asked about the Japanese cultural development of their child(ren), they replied that they are wishing their children to have a multicultural sense of identity. Parents' own cultural participation seems more skewed towards Nepalese community events due to several reasons such as sense of being Nepalese, easier access to the Nepalese community and cultural events, social media helping or working as a communicating tool between Nepalese, not being competent in the Japanese language, less knowledge of Japanese culture, not enough Japanese friends, etc. When asked about promoting the cultural identity of their children, interviewed parents have answered in this way.

For example, a father in his 40s working in a Japanese company explained about the role of parents and their attitudes towards celebrating Nepalese festivals. He said that parents must work progressively to transfer Nepalese cultural customs to their child(ren): "It doesn't matter where we live, we need to preserve our traditions, culture and keep going on coming generations too. If parent do not celebrate Nepalese festivals at home 
and in Nepalese community in Japan, then child(ren) will forget our festivals and customs."

The above quote illustrates how positive these parents are towards maintaining or transferring their culture to their child(ren). These parents have formed various groups based on their home city in Nepal, their affiliation based on ethnicity, interests and so on. These sorts of groups are also working as a milestone for developing and preserving their native culture in their child(ren).

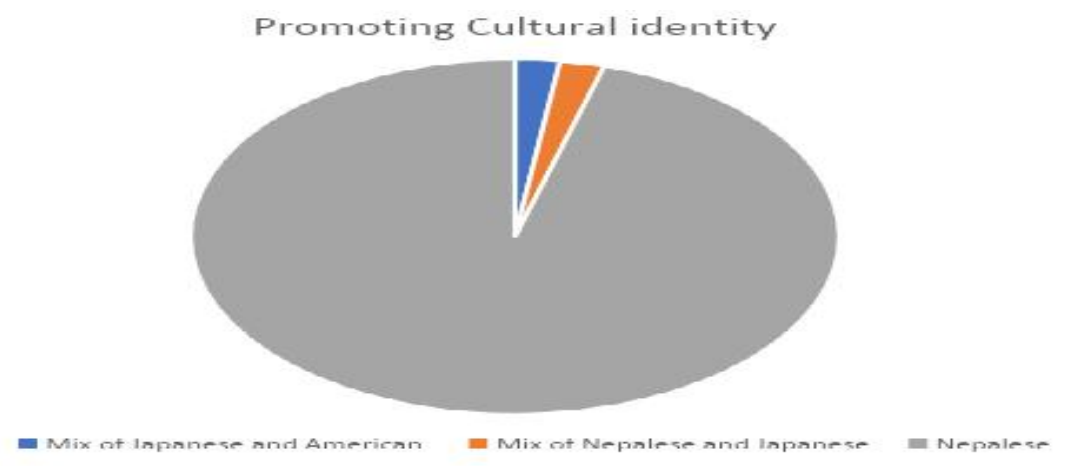

A total of 45 parents were interviewed, among them 43 parents replied that they are promoting Nepalese cultural identity for their child(ren) and only two parents answered that they are promoting a mixed cultural identity for their child(ren). One parent said their family is looking for a mix of Nepalese and Japanese cultural identity and one parent replied it was a mixture of Japanese and American culture. The parent who wished her child to be a mixture of Nepalese and Japanese has acquired a Japanese permanent residency visa. This parent said that the family is planning to live in Japan and become Japanese nationals, and they want to promote Nepalese cultural identity because they are from Nepal and this needs to be transferred to their child(ren). The family choosing a mix of Japanese and American cultural identity has one parent who was raised and educated in America and moved to Japan after marriage. This parent said that the family is not planning to go back to Nepal anymore, so they wish their child to have both Japanese and American cultural identities.

Another aspect was celebrating Nepalese and Japanese festivals with their child(ren). Parents were seen to be more active towards celebrating Nepalese festivals 
over Japanese festivals. Almost every parent replied that they are celebrating all Nepalese festivals with their child(ren) inside home and outside home but when it comes to the Japanese festivals parents seem more passive. The following chart explains more about celebrating festivals.

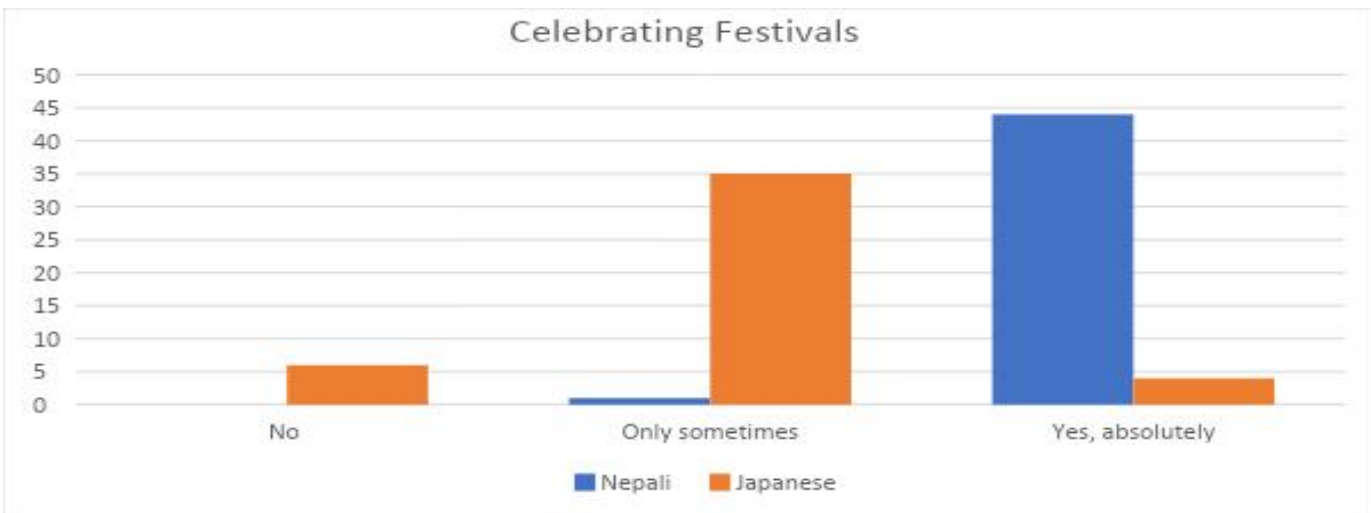

Parents have given some reasons for their festival preferences. There are several reasons behind this, including those stated in the quotes below: "Child is going to Japanese school and have many Japanese friends. Child loves Japanese festivals, so frequently visits J apanese families as well as J apanese festivals but doesn't want to take us with her due to the low J apanese ability of parents." (Mother, in her 40s and working part time)

"We are supporting Nepalese identity but no idea about the child because child is always with J apanese friends and community. So, it is hard to predict what will happen." (Mother, in her 30s and working part time)

As explained by the parents above, their children are more interested in and active towards adopting Japanese culture rather than their heritage culture. In these cases, the child is working as an agent of socialization as well as acculturation for the whole family towards Japanese culture. In these families, two dimensional or two facets of cultural identity can be seen. Where parents are more focused towards the culture of their country of origin, children are more positive towards the culture of the host nation, echoing the findings of MacDougal (2003), which suggested that cultural traditions, customs and practices are never the subject of transportation by migrants rather they are 
integrated to the local cultures. Parents were asked several questions related to cultural development of their child(ren) and which way they are focusing more, some of them showed confusion regarding transformation of their culture. But they are working through various supplements such as watching TV channels, talking with their extended family back in Nepal and visiting Nepal when they have time.

Meeting other families, or socializing in society, is the next aspect examined. Their responses are illustrated by this chart.

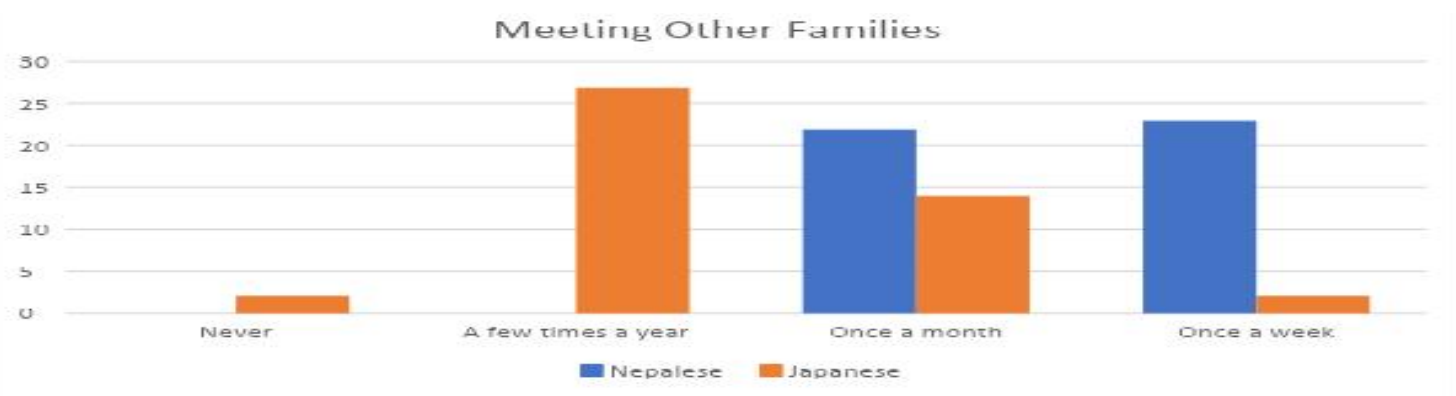

Every family said that they are meeting Nepalese families living in Tokyo in some intervals, from once a week to once a month. In contrast, there are quite a few families who replied that they rarely met any Japanese families. One of the parents explained in this way:

"We don't have Japanese friends, whom we can visit because I work in a Nepalese owned restaurant and child goes to Nepalese international school, although we wish to meet Japanese families. Once I approached a Japanese family who are living in the same building, but my Japanese ability is not enough to communicate and drag their attention towards us. (Father, living in Japan for 7 years and working in Nepalese owned curry shop)

This family has been living in Japan for more than five years and the father works in a Nepalese owned restaurant as a chef and the mother holds a number of part time jobs. The child is attending the Nepalese International school, where the Japanese language exposure is fairly low. The host country policy of segregation and exclusion (Alba \& Nee, 1997) is becoming more prominent in the assimilation process of these 
foreign families in Japan This illustrates the nature of society and how closed Japanese society is to foreigners.

Food is one of the major areas of developing a sense to belongingness. Nepalese food is more popular among these Nepalese families when it comes to cooking at home. Parents' also agree that they eat Japanese food in their daily life outside of the home.

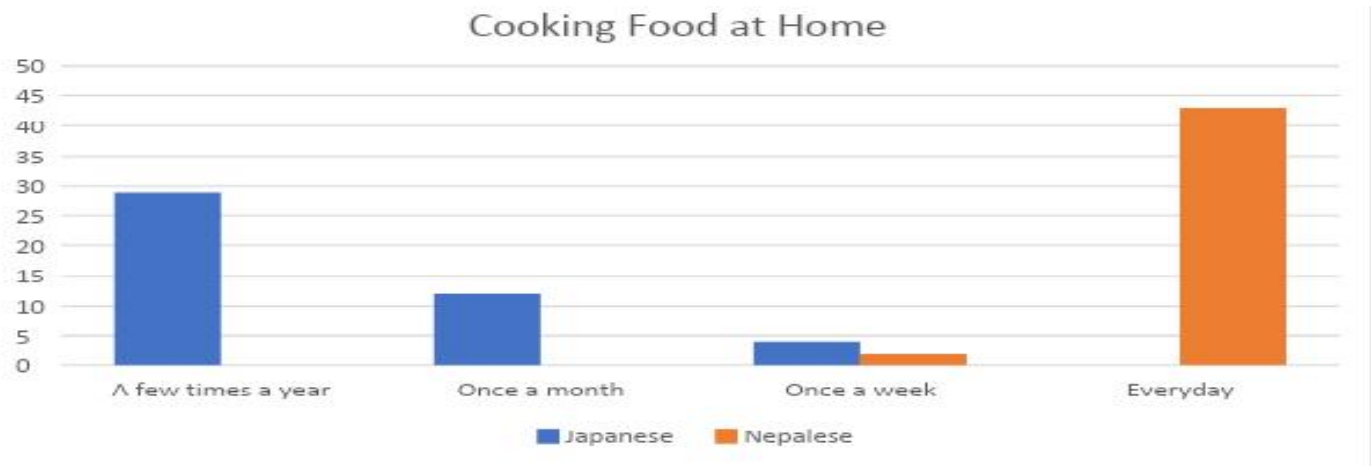

When parents' were asked about cooking food at home, 43 parents replied that they are cooking Nepalese food at home every day and only 2 parents replied that they cook Nepalese food once or twice a week. But regarding Japanese food, there are very few families cooking Japanese food regularly at home. There were several reasons behind the preference for Nepalese food: "We don't eat beef and pork, but it's difficult to read J apanese for us, so we basically focus on Nepalese food". (Mother, living in Japan for 7 years, working in part-time employment)

"Less knowledge of recipe and feel that Nepalese food is more delicious than Japanese." (Father, living in Japan for 11 years, working in a Nepalese owned restaurant)

These parents insisted that their ability to read Japanese is poor, and they don't eat beef and pork due to their religion. Nepalese food is spicier than Japanese which is preferred by Nepalese people. There are many shops in the Tokyo area where these Nepalese families can buy Nepalese ingredients, which helps them to cook their food. Food is a major part of culture and these respondents feel closer to Nepalese food rather than Japanese food. 


\section{Conclusion}

These migrant Nepalese parents are more drawn towards Nepalese cultural identity development of their child(ren) due to their own affiliation to Nepalese culture, supporting findings by Phinney (1990). Choices related to participation in communities, celebrating festivals, and food selection seem to be dominated by Nepalese culture rather than the Japanese counterparts. However, parents wish for development of a multicultural sense of identity for their child(ren), which confirms the findings of Phinney, Horenczyk, Liebkind, and Vedder (2001), who propose that cultural identities mean representing different ethnic groups for migrants or ethnically mixed people. Religious factors and language seem to be determining factors for these families leaning towards a Nepalese identity, echoing thoughts by Eisenstadt (1965) that maintaining two identities is difficult due to the big gap between those two cultures. Japan is more or less considered to be an ethnically homogenous country (Oikawa \& Yoshida, 2007) and this appears to have an impact on these Nepalese parents when they try to integrate into the Japanese community. As mentioned by Ogawa (2008), the Japanese community needs to display a more "open mind-set" (p. 91). Relatively newcomers to Japan, the Nepalese population has already established an impact in the society. As their number increases, so do issues regarding the acculturation of both the parents and the children.

\section{References}

Akhtar, S. (1994). A third individuation: immigration, identity, and the psychoanalytic process. Journal of American Psychoanalytic Association, 43 (4), 1051-1084.

Alba, R., \& Nee, V. (1997). Rethinking assimilation theory for a new era of immigration. International Migration Review, 31 (4), 826-874

Arnett, J. J. (2000). Emerging Adulthood: A theory of development From the Late Teens Through the Twenties. American Psychologist, 55 (5), 469-480.

Arnett, J. J. (2002). The psychology of globalization. American Psychologist, 57 (10), 774-783.

Bar-Yosef, R. W. (1968). De-socialization and re-socialization: the adjustment process of immigrants. International Migration Review, 2, 27-43.

Creswell, J. W. (2012). Qualitative inquiry and research design: Choosing among five approaches. Thousand Oaks, California: Sage.

Dasen, P. R. (2000). Rapid social change and the turmoil of adolescence: A cross-cultural perspective. International Journal of Group Tensions, 29 (1), 17-49. 
E-stat. (2018). Statistics of Japan. Retrieved from https://www.e-stat.go.jp/statsearch/files?page $=8 \&$ layout $=$ dataset $\&$ toukei $=00250012 \&$ kikan $=00250 \&$ stat_infid $=000004032096 \&$ metadata $=1 \&$ data $=1$

Eisenstadt, S. N., (1995). The absorption of immigrants. Free Press, Glencoe, Illinois.

Erikson, E., (1968). Identity: Youth and Crisis. New York, W. W. Norton \& Company.

Hall, S. (1993). Culture, community \& nation. Cultural Studies, 7(3), 349-363.

Lal, B. B. (1995). Symbolic interaction theories (Theories of ethnicity). American Behavioral Scientist, 38 (3), 421-442.

MacDougal, J.P. (2003). Transnational commodities as local cultural icons: Barbie dolls in Mexico. The Journal of Popular Culture, 37(2), 257-275.

Nguyen, N. A., \& Williams, H. L. (1989). Transition from East to West: Vietnamese adolescents and their parents. Journal of the American Academy of Child \& Adolescent Psychiatry, 28 (4) 505-515.

Ogawa, E. (2008). Identity choices by parents of multicultural children. Tokyo International University Language Communication Journal, 4, 75-100.

Oikawa, S., Yoshida, T. (2007). An identity based on being different: Factors on Biethnic individuals in Japan. International Journal of Intercultural Relations, 31, 633653.

Phinney, J. S. (1990). Ethnic identity in adolescents and adults: Review of research. Psychological Bulletin, 108, 499-514.

Phinney, J. S., \& Ong, A. D. (2007). Conceptualization and measurement of ethnic identity: current status and future directions. Journal of Counselling Psychology, 54 (3), 271-281.

Phinney, J. S., Horenczyk, G., Liebkind, K., \&Vedder, P. (2001). Ethnic identity, immigration, and well-being: An interactional perspective. Journal of Social Issues, 57, 493-510.

Schwartz, S. J., Montgomery, M., \& Briones, E., (2006). The role of identity in acculturation among immigrant people: Theoretical propositions, empirical questions, and applied recommendations. Human Development, 49, 1-30.

Tajfel, H., \& Turner, J. (1986). The social identity theory of intergroup behavior. In W. S. Worchel G. \& Austin (Eds.), Psychology of intergroup relations, 7-24. Chicago: Nelson-Hall. 